
$\$$ Research Square
Preprints are preliminary reports that have not undergone peer review.
They should not be considered conclusive, used to inform clinical practice, or referenced by the media as validated information.

\title{
The characteristics of antimicrobial resistance and treatment of carbapenem- resistant Enterobacteriaceae infections in children from 2013 to 2018 in a chinese tertiary hospital
}

\author{
Xiu-Qin Jia \\ Institut of Immunopharmaceutical Sciences \\ Feng Pang \\ Clinical Laboratory \\ Xin Luo \\ Joint Molecular Pharmacology \\ Jian Zhang ( $\sim$ dgqb1231@163.com) \\ Institute of Immunopharmaceutical Sciences
}

\section{Research article}

Keywords: carbapenem-resistant Enterobacteriaceae, antibiotics, infection, outcome, treatment

Posted Date: July 1st, 2019

DOI: https://doi.org/10.21203/rs.2.10825/v1

License: () (1) This work is licensed under a Creative Commons Attribution 4.0 International License. Read Full License 


\begin{abstract}
Background The aim of this study was to performe a retrospective analysis of prevalence and treatment of carbapenem-resistant Enterobacteriaceae (CRE) infections in children in a tertiary hospital. Methods The non-repeat clinical isolates of CRE in children were collected in Liaocheng People's Hospital from January, 2013 to December, 2018. The bacterial identification and antibiotic susceptibility was performed according to the standard methods. The isolated strains will be detected carbapenemases genotypes and homology analysis. All data on the culture-positive strains and associated clinical infection from different pediatric wards were reviewed. Results A total of 20 CRE strains isolated from pediatric patients, which derived from different infection sites and present a classification of multiple species of Enterobacteriaceae. And the production of IMP-type carbapenemase in these strains is the main reason of antimicrobial resistance. Most of the infected patients have severe comorbidities and invasive procedures, and use insensitive drugs due to the high resistance rates and medication restrictions. Nevertheless, most infected children have been treated despite the resistance of pathogens to multiple antimicrobial agents. In our follow-up survey, most children received adjuvant therapy such as human intravenous immunoglobulin, which may be an important factor in helping patients defeat pathogenic bacteria. Conclusions This study demonstrates a high prevalence of IMP-mediated CRE infection in pediatric patients with severe comorbidities and invasive procedures. Most children have been cured, which may be related to application of adjuvant therapy and weaker pathogenicity of the IMP-type Enterobacteriaceae.
\end{abstract}

\title{
Background
}

Enterobacteriaceae is a common pathogen for nosocomial infections and community-acquired infections. In the past decade, carbapenem-resistant Enterobacteriaceae (CRE) have emerged as a significant public health threat and begun to spread worldwide [1, 2]. CRE have been sporadically reported in Asia in recent years [3]. Carbapenem antibiotics have been used as the most effective drugs for the treatment of these severe infections. However, with the widespread use of imipenem and meropenem, CRE is increasing year by year. Due to the multiple drug resistance mechanisms produced by $\mathrm{CRE}$, the selection of antimicrobial agents for the treatment of CRE infection poses great challenges $[1,3,4]$. A study on CRE infection showed that CRE can cause many serious infections, such as pneumonia, intra-abdominal infections, urinary tract infections, and device-related infections. Depending on the treatment, about 600 people die from CRE infection each year and can cause $18 \%$ to $48 \%$ mortality [5].

In children, CRE infection is an uncommon but very serious problem that may be associated with significant mortality and long-term hospitalization. Children with CRE infections are often very weak and severe, and have potential risk factors such as comorbidities, presence of indwelling devices, surgical history, and immunosuppressive agents [6]. In East Delhi of India, a study demonstrated that 8.7\% CRE gut colonization in neonates. The risk factors for CRE gut colonization were duration of hospitalization, nasogastric (NG) tube, NG feeding, lack of breastfeeding, top feeding, ventilation, and antibiotics administration [7]. Three carbapenem-resistant Klebsiella pneumoniae isolates recovered from pediatric patients at a single U.S. health care facility, and no patients with these CRE isolates had a history of international travel. The isolates were resistant to carbapenems and produce an MBL carbapenemase, which not previously published as present among Enterobacteriaceae in the United States [8]. CRE infection remains a growing problem in pediatric populations. Few studies have used rigorous methods to guide children's treatment options, and the data must be inferred from adult literature. After children are infected with $\mathrm{CRE}$, the choice of treatment will be more limited due to restrictions on antibiotics for children [9-12]. Here we retrieved pediatric CRE infection cases from 2013 to 2018 in a tertiary general hospital. Strain information and infection data were analyzed to help guide the control of future CRE infections in children.

\section{Methods \\ Setting and study design}

The non-repeat clinical isolates of CRE in children were collected from Liaocheng People's Hospital, a chinese tertiary comprehensive hospital. The children patients infected with CRE strains were from neonatal intensive care units (NICU), pediatric intensive care unit (PICU), neonatology, pediatric surgery and pediatrics ward. Patients were included if CRE pathogens identified from respiratory, blood, urine, superficial pus, bile, deep pus or sterile body fluid samples from January 1, 2013 to December 31, 2018. This study focused on bacterial strains, and retrospectively analyzed infection-related indicators and clinical data of infected hosts, which were already existing fully de-identified retrospective data. According to the Medical Ethics Committee of Liaocheng People's Hospital and local ethics regulations, this study was exempt from IRB review.

All positive CRE cultures and associated clinical infection data from different pediatric wards were reviewed. The same patient with recurrent infections were defined only once infection. In cases of concurrent infection, patients were classified according to the primary CRE infection. Patients' data were compiled until death or hospital discharge. The basic clinical and drug resistance datas with CRE infection in pediatric patients were investigated, such as isolation genotype, drug susceptibility result, ward, underlying disease, invasive procedure, treatment and outcome due to CRE.

\section{Detection of carbapenemases and molecular typing}

The bacterial identification was performed using a Vitek MS automated mass spectrometry detection system, and antibiotic susceptibility was operated by Vitek 2 compact automated system. PCRs were performed for bla ${ }_{K P C}, b / a_{V I M}, b / a_{I M P}, b / a_{N D M-1}$ and $b / a_{O X A-48}$ genes as Table 1 . The amplicons were sequenced in Shanghai Sangon company, sequencing instruments and reagents were ABI-PRISM 3730 and BigDye terminator v3.1 respectively. Then the sequencing results blasted to NCBI databases (www.ncbi.nlm.nih. gov/) to identify genetype and registered to GenBank sequence database.

The homology of strains harboring carbapenemase genes were determined by using pulse-field gel electrophoresis (PFGE) analysis. The restriction enzyme was Xba 1, and Salmonella Braenderup $\mathrm{H} 9812$ strain DNA was used as standard size markers. The genetic relationship of the test strains was generated by

Page 2/10 
the unweighted pair-group method (UPGMA). Isolates that exhibited a PFGE profile with more than $80 \%$ similarity (pulsotype, PT) were considered as closely related strains.

\section{Definitions}

Children was defined if patients were no elder than 14 years old.

CRE was defined as organisms of Enterobacteriaceae showing decreased susceptibility to any carbapenem antibiotic, including ertapenem minimum inhibitory concentration (MIC) $\geq 1 \mu \mathrm{g} / \mathrm{ml}$, meropenem MIC $\geq 2 \mu \mathrm{g} / \mathrm{ml}$, or imipenem MIC $\geq 2 \mu \mathrm{g} / \mathrm{ml}$, using current Clinical and Laboratory Standards Institute breakpoints [13].

\section{Results}

\section{Infected strain and carbapenemaase information}

Twenty cases of CRE infection in children patients were identified: seven Escherichia coli, six Klebsiella pneumoniae, two Klebsiella oxytoca, two Enterobacter aerogenes, two Serratia marcescens, one Enterobacter cloacae. PFGE revealed that two E. coli and three K. pneumoniae had an indistinguishable PFGE pattern, while the other isolates were different strains. The production of IMP-type carbapenemase was the main antibiotic resistance mechanism. Confirmed by sequencing, twelve strains of CRE were produced IMP-4 type carbapenemase, which included four E. coli, two K. pneumoniae, two K. oxytoca, two $E$. aerogenes, one $S$. marcescens and one $E$. cloacae. While seven strains of CRE were confirmed to produce IMP-8 carbapenemase, including three $K$. pneumoniae, three E. coli and one S. marcescens, one strain did not detect the carbapenemase genetype.

\section{The characteristics of antimicrobial resistance}

The isolated CRE strains show highly resistant to carbapenems and cephalosporins (ertapenem 70.0\%, imipenem 95.0\%, meropenem $90.0 \%$, ceftriaxone $85.0 \%$, ceftazidime $80.0 \%$ and cefepime $75.0 \%$ ). The resistance rate to trimethoprim/sulfamethoxazole, tobramycin and ciprofloxacin were relatively low $(55.0 \%, 45.0 \%$ and $30.0 \%)$, while no resistance to tigecycline was observed.

\section{Infection types and patient characteristics}

The sources of cultures were respiratory (50.0\%), blood (30.0\%), lavage fluid (10.0\%) and wound secretion (10.0\%) (Table 2). Neonatology and pediatrics ward were the most frequent residence of pathogen (each six cases), followed by PICU (four cases), NICU (two cases) and pediatric Surgery (two cases). The age of pediatric patients was from one day to eight years old and male accounted for the majority in these patients $(15 / 20,75.0 \%)$. Most patients have comorbidities such as premature, gastrointestinal dysfunction and coronary heart disease, seven patients (35.0\%) experienced invasive procedures such as mechanical ventilation, bronchoalveolar lavage (Table 3).

\section{Treatment and outcomes}

The majority $(15 / 20,75.0 \%)$ of patients were treated with monotherapy (third-generation cephalosporin, piperacillin/tazobactam or carbapenem) for empiric treatment. Compound sulfamethoxazole was used as single-drug therapy in two cases, one improved and the other abandon treatment due to the primary disease. Although most patients received the insensitive antibacterial drugs due to the limitations of children, outcomes were still optimistic (two cured, $10.0 \%$; thirteen improved, 65.0\%). In addition to the application of antibiotics, most children (80.0\%) took ancillary treatments such as human intravenous immunoglobulin.

\section{Discussion}

In recent years, along with the rapidly increasing prevalence of CRE worldwide in the adult, CRE have been reported occasionally in children [14]. Once the children infected with CRE, clinical treatment measures are very limited due to fewer antimicrobial options. Currently it is still unclear about the optimal treatment regimens for CRE because of the lack data of randomized trials evaluating in various therapeutic approaches. To date, there are no authoritative guidelines recommending medications for children infected with CRE. only case series, case reports, or cohort studies with significant heterogeneity in population and treatment regimens were evaluated [5]. Available data support combination therapy may be beneficial to patients, however, there are insufficient data to recommend a particular combination regimen [15-17]. In our study, the resistance rates of tobramycin, ciprofloxacin and tigecycline were relatively low, but no children were treated with these drugs due to serious potential side effects such as ear nephrotoxicity, malformation, tooth or joint development especially for infants. On the contrary, $75.0 \%$ of patients have been implemented insensitive monotherapy antibiotics for empiric treatment. After the drug sensitivity report was obtained, there was still no replacement of the antibacterial drug due to the limitation of selection and the improvement of clinical symptoms. Fortunately, the infection status of most children has gradually improved. In our follow-up survey, we found that most children received adjuvant therapy which may be an important factor in helping patients defeat pathogenic bacteria. Overall, antibiotic selection should be guided by local susceptibility patterns, clinical source of infection and expert consultation. 
CRE have been isolated throughout Europe, parts of Asia and Africa, and in the United States, often in individuals who have traveled from endemic regions [2]. The mechanism of resistance to CRE is mainly the production of carbapenemases. Isolates that exhibited phenotypic resistance to carbapenems were tested with primers for bla genes that encode class A (KPC), class B (NDM, IMP and VIM), and class D (OXA-48) carbapenemases. In the report of pediatric infection with $\mathrm{CRE}$, different bla genotype infections have also appeared. The class A carbapenemase in KPC in paediatric hospital isolated in the USA and UK [10, 11, 14]. And class B including NDM, IMP and VIM has been described in India, USA and Spain respectively [3, 8, 18]. A outbreak of OXA-48 (class D) begun in 2012 (16 cases in NICU and 1 in PICU) confirmed that all the microorganisms isolated from children belonged to the same strain (ST11) [19]. The combination of these reports, KPC is still a major genotypes carbapenemases type in CRE infections, other genotypes are relatively small. Our study confirms that the IMP type is entire type of carbapenemase, indicating that there are still large differences between regions. Therefore, this different genotype needs to be considered when formulating the corresponding antibacterial strategy. In addition, we observed that the CRE strain producing KPC appeared to be more pathogenic and reported higher mortality $[8,16]$. This may suggest the weaker pathogenicity of IMP than KPC produced by Enterobacteriaceae.

From different reports, the site of infection with CRE and the source of the specimen are not the same. At the same time, the genus of Enterobacteriaceae is different. One study by Zerr DM et al.on clinical epidemiology of CRE at four US pediatric hospitals showed the most common CRE pathogens were E. coli, followed by K. pneumoniae [20], which is the same to our study. But the specimen distribution in this study is mainly urine, which is different from our findings mainly in respiratory specimens. And blood infections accounted for the second place in our study. Although specimens and sources are very different in the report of CRE infection, K. pneumoniae and E.coli occupies most isolates in Enterobacteriaceae. Despite this, we have found CRE infections in several species, including two K. oxytoca, two E. aerogenes, two S. marcescens and one E. cloacae. Currently CRE in these strains reports are rare.

Much anti-infective research have evaluated the efficacy of treating CRE aspects. Available data suggest that carbapenem-containing combination therapy may be effective over monotherapy or non-carbapenem containing combination therapy [15-16]. Carbapenems remain a mainstay of pediatric therapy of CRE infections based on the available adult experience and literature despite the high resistance rates [14]. However, few data exist on the potential benefit of carbapenems in the pediatric population. One study about the risk factors for mortality with CRE bloodstream infection in children showed they were unable to assess whether combination therapy including meropenem was more effective than combination therapy without meropenem, because the mortality rate in children who received meropenem for an isolate with an MIC > $8(100.0 \%, n=8)$ was significantly higher than that with $\mathrm{MIC} \leq 8 \mathrm{mg} / \mathrm{L}(45.5 \%, \mathrm{n}=22)[17]$. Although carbapenem resistance means that the strain is resistant to any carbapenems, for our study the resistance rate of ertapenem (70.0\%), imipenem $(95.0 \%)$ and meropenem $(90.0 \%)$ is different. Accordingly, the resistance mechanism of the same isolate to different carbapenems is not the same. How to apply carbapenem antibiotics to treat CRE infection in children still needs further study.

Tigecycline-antibacterial drugs that need to be focused on because of the possibility of treating CRE infection. One study about susceptibility rates among Enterobacteriaceae isolates collected from pediatric patients (< 18 years of age) from 2004 to 2012, showed the highest susceptibility rates of tigecycline among Enterobacteriaceae isolates were E. Coli and K. oxytoca (100.0\% each), followed by Enterobacterspp. (97.6\%), K. pneumoniae ( $96.3 \%)$ and S. marcescens ( $91.5 \%$ each) in Asian region [21]. Similar results were obtained in our study, the susceptibility rate of tigecycline among CRE isolates is $100.0 \%$. However, tigecycline is not currently indicated for the treatment of infections in patients $<18$ years of age, and it should be used for pediatric patients only when no alternative antimicrobial agents are available. In pediatric settings, experience with tigecycline is limited to case reports, and along with the potential for increased mortality, association with enamel hypoplasia, tooth discoloration [22]. Purdy et al. recently reported the pharmacokinetic properties, safety profile, and efficacy of tigecycline in pediatric patients eight to eleven years of age. Their results show use of tigecycline among patients under eight years of age is not recommended because of possible effects on tooth development [23].

Study the risk factors of CRE infection in children, which will make infection prevention more effective. Several studies have evaluated risk factors include underlying chronic medical conditions, invasive medical devices, frequent or prolonged hospitalizations, prior antibiotic exposure, age and travel from endemic regions [24]. Nour I et al. [25]also have evaluated the duration of total parenteral nutrition and carbapenem use were the independent predictors for CRE acquisition. In our study, underlying disease, gender (male, 75.0\%), young age and invasive procedures were considered important risk factors for CRE infection. Therefore, effective active surveillance, infection prevention and control for risk factors of CRE is an important public health issue. Adequate attention must be given to prevent the spread of CRE for children patients in each region hospitals. One study by Millar et al. on predictors for gut colonization of CRE in a NICU showed active surveillance of cultures from hospitalized patients and implementation of preventive efforts can reduce the risk of CRE [7]. Therefore, the future controlled studies are necessary to assess risk factors and antibiotic policies in hospital to ensure the appropriate therapeutic selection in children.

Several limitations should be considered in our research. Firstly, although this study included all children with CRE infection in our hospital for six consecutive years, the number of cases is still limited and only preliminary conclusions can be drawn. Subsequent specific treatment options need to be based on the expansion of big data in the relevant infection research area. Secondly, different physicians choose different empirical treatment options during antibiotic treatment, and this is our first concern of these CRE-infected children, so far we still have not found a uniform treatment strategy. Thirdly, our study only found that the IMP genotype in our region, which is not the same as the genotype reported in other regions, and may lead to differences in treatment options.

\section{Conclusions}

CRE infection has a prevalent trend in children patient in our hospital, and the drug-resistant genotypes detected within six years are unusually IMP-mediated. Despite the high rate of resistance and the limitations of medications for children, most patients have improved after using insensitive antibiotics. The adjuvant therapy and weaker pathogenicity of IMP-mediated CRE isolates may be responsible for desired outcomes in children. In addition, the urgent problem to be solved is to establish an optimal treatment and control program for the spread of CRE in children. 


\begin{abstract}
Abbreviations
CRE: carbapenem-resistant Enterobacteriaceae; ICU: intensive care units; NICU: neonatal intensive care units; PICU: pediatric intensive care unit; PFGE: pulsefield gel electrophoresis; UPGMA: unweighted pair-group method; SMA: Serratia marcescens; KOX: Klebsiella oxytoca; ECO: Escherichia coli; KPN: Klebsiella pneumonia; EAE: Enterobacter aerogenes; ECL: Enterobacter cloacae,MIC: minimum inhibitory concentration; M: male; F: female; NRF: neonatal respiratory failure; HIE: hypoxic-ischemic encephalopathy; CPR: cardiopulmonary resuscitation; MODS: multiple organ disfunction syndrome; CHD: congenital heart disease; ALL: acute lymphoblastic leukemia; ICH: intracerebral hemorrhage; MDS: myelodysplastic syndrome; HBV: hepatitis B virus; GERD: gastroesophageal reflux disease; AGA: acute gangrenous appendicitis; BAL: bronchoalveolar Lavage; PE: pericardial effusion; BMA: bone marrow aspiration.
\end{abstract}

\title{
Declarations
}

\section{Ethics approval and consent to participate}

The study was a retrospective analysis of a de-identified database. As such, it is not considered human subject research.

\section{Consent for publication}

Not applicable.

\section{Availability of data and material}

All the dataset of this study is from the Liaocheng People's Hospital's internal database. If reasonably requested, it can available from the corresponding author.

\section{Competing interests}

The authors declare that they have no competing interests.

\section{Funding}

This study was funded by Natural Science Foundation of Shandong Province, China (ZR2014HL090). FP provided funds for the isolation and identification of bacteria, as well as analysis and interpretation of drug resistance genotypes.

\section{Authors' contributions}

ZJ designed this study, participated in statistic calculations and interpretation of data. XQJ drafted this manuscript and participated in statistic calculations. FP provided funds for the isolation and identification of bacteria, as well as analysis and interpretation of drug resistance genotypes. XL participated in statistic calculations. All authors read and approved the final manuscript.

\section{Acknowledgments}

Not applicable.

\section{Authors' information}

${ }^{1}$ Institute of Immunopharmaceutical Sciences, School of Pharmaceutical Sciences, Shandong University, No.44, Wenhuaxi Road, Lixia District, Jinan 250012, Shandong Province, People's Republic of China. ${ }^{2}$ Joint Molecular Pharmacology Center, Liaocheng People's Hospital, No.67, Dongchangxi Road, Dongchangfu District, Liaocheng 252000, Shandong Province, People's Republic of China. ${ }^{3}$ Department of Clinical Laboratory, Liaocheng People's Hospital, No.67, Dongchangxi Road, Dongchangfu District, Liaocheng 252000, Shandong Province, People's Republic of China.

\section{References}

1. Gupta N, Limbago BM, Patel JB, Kallen AJ. Carbapenem-resistant Enterobacteriaceae: epidemiology and prevention. Clin Infect Dis. 2011;53:60-7.

2. Nordmann P, Naas T, Poirel L. Global spread of carbapenemase-producing Enterobacteriaceae. Emerg Infect Dis. 2011;17:1791-8.

3. Sekar R, Mythreyee M, Srivani S, Sivakumaran D, Lallitha S, Saranya S. Carbapenem-resistant Enterobacteriaceae in Pediatric Bloodstream Infections in Rural Southern India. Indian Pediatr. 2017;54:1021-4. 
4. Weiner LM, Webb AK, Limbago B, Dudeck MA, Patel J, Kallen AJ, et al. Antimicrobial-resistant pathogens associated with healthcare-associated infections: Summary of data reported to the National Healthcare Safety Network at the Centers for Disease Control and Prevention, 2011-2014. Infect Control Hosp Epidemiol. 2016; 37:1288-1301.

5. Morrill HJ, Pogue JM, Kaye KS, LaPlante KL. Treatment Options for Carbapenem-Resistant Enterobacteriaceae Infections. Open Forum Infect Dis. 2015;2:ofv050.

6. Logan LK. Carbapenem-resistant enterobacteriaceae: an emerging problem in children. Clin Infect Dis. 2012;55:852-9.

7. Singh NP, Choudhury DD, Gupta K, Rai S, Batra P, Manchanda V, et al. Predictors for gut colonization of carbapenem-resistant Enterobacteriaceae in neonates in a neonatal intensive care unit. Am J Infect Control. 2018;46:e31-e35.

8. Limbago BM, Rasheed JK, Anderson KF, Zhu W, Kitchel B, Watz N, et al. IMP-producing carbapenem-resistant Klebsiella pneumoniae in the United States. J Clin Microbiol. 2011;49:4239-45.

9. Hsu AJ, Tamma PD. Treatment of multidrug-resistant Gram-negative infections in children. Clin Infect Dis. 2014;58:1439-48.

10. Stillwell T, Green M, Barbadora K, Ferrelli JG, Roberts TL, Weissman SJ, et al. Outbreak of KPC-3 Producing Carbapenem-Resistant Klebsiella pneumoniae in a US Pediatric Hospital. J Pediatric Infect Dis Soc. 2015;4:330-8.

11. Drew RJ, Turton JF, Hill RL, Livermore DM, Woodford N, Paulus S, et al. Emergence of carbapenem-resistant Enterobacteriaceae in a UK paediatric hospital. J Hosp Infect. 2013;84:300-4.

12. Chiotos K, Tamma PD, Flett KB, Naumann M, Karandikar MV, Bilker WB, et al. Multicenter Study of the Risk Factors for Colonization or Infection with Carbapenem-Resistant Enterobacteriaceae in Children. Antimicrob Agents Chemother. 2017;61. pii: e01440-17.

13. Institute CLS. Performance Standards for antimicrobial susceptibility testing; Twenty-eighth Informational Supplement, M100. CLSI: Wayne (PA); 2018.

14. Logan LK, Hujer AM, Marshall SH, Domitrovic TN, Rudin SD, Zheng X, et al. Analysis of $\beta$-Lactamase Resistance Determinants in Enterobacteriaceae from Chicago Children: a Multicenter Survey. Antimicrob Agents Chemother. 2016;60:3462-9.

15. Qureshi ZA, Paterson DL, Potoski BA, Kilayko MC, Sandovsky G, Sordillo E, et al. Treatment outcome of bacteremia due to KPC-producing Klebsiella pneumoniae: superiority of combination antimicrobial regimens. Antimicrob Agents Chemother. 2012;56:2108-13.

16. Tumbarello M, Viale P, Viscoli C, Trecarichi EM, Tumietto F, Marchese A, et al. Predictors of mortality in bloodstream infections caused by Klebsiella pneumoniae carbapenemase-producing K. pneumoniae: importance of combination therapy. Clin Infect Dis. 2012; 55:943-50.

17. Nabarro LEB, Shankar C, Pragasam AK, Mathew G, Jeyaseelan V, Veeraraghavan B, et al. Clinical and Bacterial Risk Factors for Mortality in Children With Carbapenem-resistant Enterobacteriaceae Bloodstream Infections in India. Pediatr Infect Dis J. 2017;36:e161-e166.

18. Oteo J, Hernandez-Almaraz JL, Gil-Anton J, Vindel A, Fernandez S, Bautista V, et al. Outbreak of vim-1-carbapenemase-producing Enterobacter cloacae in a pediatric intensive care unit. Pediatr Infect Dis J. 2010;29:1144-6.

19. Herruzo R, Ruiz G, Perez-Blanco V, Gallego S, Mora E, Vizcaino MJ, et al. Bla-OXA48 gene microorganisms outbreak, in a tertiary Children's Hospital, Over 3 years (2012-2014): Case Report. Medicine (Baltimore). 2017;96:e7665.

20. Zerr DM, Weissman SJ, Zhou C, Kronman MP, Adler AL, Berry JE, et al. The Molecular and Clinical Epidemiology of Extended-Spectrum Cephalosporin- and Carbapenem-Resistant Enterobacteriaceae at 4 US Pediatric Hospitals. J Pediatric Infect Dis Soc. 2017;6:366-75.

21. Kehl SC, Dowzicky MJ. Global assessment of antimicrobial susceptibility among Gram-negative organisms collected from pediatric patients between 2004 and 2012: results from the Tigecycline Evaluation and Surveillance Trial. J Clin Microbiol. 2015;53:1286-93.

22. Colombo S, Scolfaro C, Calitri C, Denina M, Carraro F, De Intinis G, et al. Carbapenemase-producing enterobacteriaceae (CPE) in the pediatric setting: results from an 18-month survey. Infect Control Hosp Epidemiol. 2014;35:599-601.

23. Purdy J, Jouve S, Yan JL, Balter I, Dartois N, Cooper CA, et al. Pharmacokinetics and safety profile of tigecycline in children aged 8 to 11 years with selected serious infections: a multicenter, open-label, ascending-dose study. Clin Ther. 2012;34:496-507.e1.

24. Chiotos K, Han JH, Tamma PD. Carbapenem-Resistant Enterobacteriaceae Infections in Children. Curr Infect Dis Rep. 2016;18:2.

25. Nour I, Eldegla HE, Nasef N, Shouman B, Abdel-Hady H, Shabaan AE. Risk factors and clinical outcomes for carbapenem-resistant Gram-negative lateonset sepsis in a neonatal intensive care unit. J Hosp Infect. 2017;97:52-8.

\section{Tables}

Table 1 Universal amplification primers of common carbapenemase genotype 


\begin{tabular}{|c|c|c|c|c|}
\hline Target segment & Universal primers & Design sequence $\left(5^{\prime}-3^{\prime}\right)$ & Product length & Annealing temperature \\
\hline \multirow[t]{2}{*}{ KPC } & KPC-F & GATGTCACTGTATCGCCGTCT & $739 \mathrm{bp}$ & $55^{\circ} \mathrm{C}$ \\
\hline & $\mathrm{KPC}-\mathrm{R}$ & ATAGTCATTTGCCGTGCCATA & & \\
\hline \multirow[t]{2}{*}{ VIM-1 } & VIM-1-F & TTATGGAGCAGCAACGATGT & $920 \mathrm{bp}$ & $54^{\circ} \mathrm{C}$ \\
\hline & VIM-1-R & CAAAAGTCCCGCTCCAACGA & & \\
\hline \multirow[t]{2}{*}{ VIM-2 } & VIM-2-F & AAAGTTATGCCGCACTCACC & $953 \mathrm{bp}$ & $54^{\circ} \mathrm{C}$ \\
\hline & VIM-2-R & TGCAACTTCATGTTATGCCG & & \\
\hline \multirow[t]{2}{*}{ IMP-1 } & IMP-1-F & TGAGCAAGTTATCTGTATTC & $740 \mathrm{bp}$ & $51^{\circ} \mathrm{C}$ \\
\hline & IMP-1-R & TTAGTTGCTTGGTTTTGATG & & \\
\hline \multirow[t]{2}{*}{ IMP-2 } & IMP-2-F & GGCAGTCGCCCTAAAACAAA & $737 \mathrm{bp}$ & $54^{\circ} \mathrm{C}$ \\
\hline & IMP-2-R & TAGTTACTTGGCTGTGATGG & & \\
\hline \multirow[t]{2}{*}{ NDM-1 } & NDM-1-F & CAACGGTTTGATCGTCAGG & $370 \mathrm{bp}$ & $56^{\circ} \mathrm{C}$ \\
\hline & NDM-1-R & GATCCCAACGGTGATATTGTC & & \\
\hline \multirow[t]{2}{*}{ OXA-48 } & OXA-48-F & AAGGGGACGTTATGCGTGTAT & $781 \mathrm{bp}$ & $55^{\circ} \mathrm{C}$ \\
\hline & OXA-48-R & ACTTCTTTTGTGATGGCTTGG & & \\
\hline
\end{tabular}

Table 2 Antimicrobial susceptibility profiles of carbapenem-resistant Enterobacteriaceae isolated from pediatric patients 


\begin{tabular}{|c|c|c|c|c|c|c|c|c|c|c|c|c|}
\hline \multirow[t]{2}{*}{ Isolate $^{a}$} & \multirow[t]{2}{*}{ Year } & \multirow[t]{2}{*}{ Specimen } & \multirow[t]{2}{*}{ Genotype } & \multicolumn{9}{|c|}{ Antimicrobial agent and $\mathrm{MIC}^{\mathrm{b}}(\mu \mathrm{g} / \mathrm{mL})$} \\
\hline & & & & Ertapenem & Imipenem & Meropenem & Gentamicin & Tobramycin & Piperacillin/tazobactam & Ceftriaxone & Ceftazidime & Cef \\
\hline SMA1 & 2013 & Blood & blaIMP-4 & $\leq 0.5$ & 4 & 2 & $\leq 1.0$ & 2 & $\leq 4$ & $\leq 1.0$ & $\leq 1.0$ & $\leq$ \\
\hline SMA2 & 2013 & Blood & blaIMP-8 & $\leq 0.5$ & 4 & 2 & $\leq 1.0$ & 2 & $\leq 4$ & 2 & $\leq 1.0$ & $\leq$ \\
\hline KOX1 & 2013 & Blood & blaIMP-4 & $\geq 8$ & 8 & $\geq 16$ & $\geq 16$ & 8 & $\geq 128$ & $\geq 64$ & $\geq 64$ & $\geqq$ \\
\hline ECO1 & 2014 & Respiratory & blaIMP-4 & 2 & $\leq 1.0$ & $\geq 16$ & $\leq 1.0$ & $\leq 1.0$ & 64 & $\geq 64$ & $\geq 64$ & $\vdots$ \\
\hline KPN1 & 2014 & Respiratory & blaIMP-8 & $\geq 8$ & $\geq 16$ & $\geq 16$ & $\geq 16$ & 8 & $\geq 128$ & $\geq 64$ & $\geq 64$ & $\geq$ \\
\hline $\mathrm{ECO} 2$ & 2014 & $\begin{array}{c}\text { Lavage } \\
\text { fluid }\end{array}$ & blaIMP-4 & $\leq 0.5$ & 4 & $\geq 16$ & $\geq 16$ & 8 & 64 & $\geq 64$ & $\geq 64$ & \\
\hline ECO3 & 2015 & Blood & blaIMP-8 & $\geq 8$ & $\geq 16$ & $\geq 16$ & $\geq 16$ & 2 & $\geq 128$ & $\geq 64$ & $\geq 64$ & $\vdots$ \\
\hline KOX2 & 2015 & Blood & blaIMP-4 & $\geq 8$ & $\geq 16$ & $\geq 16$ & $\geq 16$ & 4 & 64 & $\geq 64$ & $\geq 64$ & \\
\hline EAE1 & 2016 & Respiratory & blaIMP-4 & $\leq 0.5$ & 4.0 & 4 & $\leq 1.0$ & $\leq 1.0$ & $\leq 4.0$ & $\leq 1.0$ & $\leq 1.0$ & $\leq$ \\
\hline KPN2 & 2016 & Respiratory & blaIMP-8 & $\geq 8$ & $\geq 16$ & $\geq 16$ & $\geq 16$ & 2.0 & $\geq 128$ & $\geq 64$ & $\geq 64$ & $\geqq$ \\
\hline KPN3 & 2017 & Respiratory & blaIMP-4 & $\geq 8$ & $\geq 16$ & $\geq 16$ & $\geq 16$ & $\geq 16$ & $\geq 128$ & $\geq 64$ & $\geq 64$ & $\geqq$ \\
\hline $\mathrm{ECO} 4$ & 2017 & Respiratory & blaIMP-8 & $\geq 8$ & $\geq 16$ & $\geq 16$ & $\geq 16$ & $\geq 16$ & $\geq 128$ & $\geq 64$ & 16 & $\geqq$ \\
\hline KPN4 & 2017 & $\begin{array}{c}\text { Lavage } \\
\text { fluid }\end{array}$ & None & 4.0 & 4.0 & $\geq 16$ & $\leq 1.0$ & $\leq 1.0$ & 8.0 & $\geq 64$ & $\geq 64$ & $\geqq$ \\
\hline EAE2 & 2017 & Respiratory & blaIMP-4 & $\leq 0.5$ & 4.0 & $\leq 1.0$ & $\leq 1.0$ & $\leq 1.0$ & $\leq 4.0$ & $\leq 1.0$ & $\geq 64$ & $\leq$ \\
\hline $\mathrm{ECO} 5$ & 2017 & $\begin{array}{c}\text { Wound } \\
\text { secretion }\end{array}$ & blaIMP-4 & $\geq 8$ & 4.0 & $\geq 16$ & $\geq 16$ & $\geq 16$ & $\geq 128$ & $\geq 64$ & $\geq 64$ & $\geq$ \\
\hline KPN5 & 2017 & Respiratory & blaIMP-8 & $\geq 8$ & $\geq 16$ & $\geq 16$ & $\geq 16$ & 8 & $\geq 128$ & $\geq 64$ & $\geq 64$ & \\
\hline ECO6 & 2018 & Respiratory & blaIMP-4 & $\geq 8$ & 8 & $\geq 16$ & $\geq 16$ & $\geq 16$ & $\geq 128$ & $\geq 64$ & $\geq 64$ & $\geqq$ \\
\hline ECL1 & 2018 & Blood & blaIMP-4 & $\leq 0.5$ & 4.0 & $\leq 1.0$ & $\leq 0.5$ & 4.0 & 16.0 & 32.0 & 16.0 & $\leq$ \\
\hline KPN6 & 2018 & Respiratory & blaIMP-4 & $\geq 8$ & $\geq 16$ & $\geq 16$ & $\geq 16$ & 8 & $\geq 128$ & $\geq 64$ & $\geq 64$ & $\geq$ \\
\hline $\mathrm{ECO} 7$ & 2018 & $\begin{array}{c}\text { Wound } \\
\text { secretion }\end{array}$ & blaIMP-8 & $\geq 8$ & $\geq 16$ & $\geq 16$ & $\leq 1.0$ & $\leq 1.0$ & $\geq 128$ & $\geq 64$ & $\geq 64$ & 1 \\
\hline
\end{tabular}

a SMA, Serratia marcescens; KOX, Klebsiella oxytoca; ECO, Escherichia coli; KPN, Klebsiella pneumonia; EAE, Enterobacter aerogenes; ECL, Enterobacter cloacae.

$\mathrm{b}_{\mathrm{MIC}}$, minimum inhibitory concentration

Table 3 Characteristics of pediatric patients with carbapenem-resistant Enterobacteriaceae 


\begin{tabular}{|c|c|c|c|c|c|c|}
\hline $\begin{array}{l}\text { Patient } \\
\text { number/ } \\
\text { Isolate }^{a}\end{array}$ & Ward $^{b}$ & Underlying disease $\mathrm{e}^{C}$ & $\begin{array}{l}\text { Invasive } \\
\text { procedure }^{d}\end{array}$ & Infection due to $\mathrm{CRE}^{e}$ & Directed antibiotic therapy & Outcome \\
\hline 1/ SMA1 & NICU & $\begin{array}{l}\text { Premature infant, neonatal } \\
\text { pneumonia, NRF, HIE }\end{array}$ & $\begin{array}{l}\text { Mechanical } \\
\text { ventilation }\end{array}$ & Neonatal pneumonia & $\begin{array}{l}\text { Piperacillin/tazobactam, } \\
0.10 \mathrm{~g}, \text { bid, } 14 \text { days }\end{array}$ & Improve \\
\hline 2/ SMA2 & NICU & $\begin{array}{l}\text { Premature infant, neonatal } \\
\text { pneumonia }\end{array}$ & None & Neonatal pneumonia & $\begin{array}{c}\text { Piperacillin/tazobactam, } \\
\text { 0.06g, bid, } 19 \text { days }\end{array}$ & Unknown \\
\hline 3/ KOX1 & PICU & $\begin{array}{l}\text { Sepsis, intracranial infection, } \\
\text { liver damage }\end{array}$ & None & $\begin{array}{l}\text { Sepsis, intracranial } \\
\text { infection }\end{array}$ & $\begin{array}{l}\text { Ceftriaxone, } 1 \mathrm{~g} \text {, qd, } 14 \text { days and } \\
\text { meropenem, } 0.4 \mathrm{~g} \text {, q8h, } 18 \text { days }\end{array}$ & Unknown \\
\hline 4/ ECO1 & Neonatology & Bronchopneumonia, NRF & $\begin{array}{l}\text { Mechanical } \\
\text { ventilation }\end{array}$ & Bronchopneumonia & Imipenem, $0.03 \mathrm{~g}, \mathrm{q} 6 \mathrm{~h}, 3$ days & Cure \\
\hline 5/ KPN1 & PICU & $\begin{array}{c}\text { Bronchopneumonia, CPR, } \\
\text { HIE, MODS }\end{array}$ & $\begin{array}{l}\text { Mechanical } \\
\text { ventilation }\end{array}$ & Bronchopneumonia & Ceftriaxone, $0.5 \mathrm{~g}$, qd, 10 days & $\begin{array}{l}\text { Abandon } \\
\text { treatment }\end{array}$ \\
\hline 6/ ECO2 & PICU & Severe pneumonia, CHD & BAL & Severe pneumonia & Ceftizoxime, $0.25 \mathrm{~g}$, q8h, 8 days & Improve \\
\hline 7/ ECO3 & PICU & $\begin{array}{l}\text { Septicemia, ALL, } \\
\text { Bronchopneumonia }\end{array}$ & $\begin{array}{l}\text { Mechanical } \\
\text { ventilation }\end{array}$ & $\begin{array}{l}\text { Bronchopneumonia, } \\
\text { septicemia }\end{array}$ & $\begin{array}{l}\text { Amikacin, } 0.1 \mathrm{~g}, \mathrm{q} 12 \mathrm{~h} \text { and caspofungin } \\
\text { 31.25mg, qd, } 3 \text { days }\end{array}$ & $\begin{array}{l}\text { Abandon } \\
\text { treatment }\end{array}$ \\
\hline $8 / \mathrm{KOX} 2$ & Pediatrics & Intracranial infection, sepsis & None & $\begin{array}{c}\text { Intracranial infection, } \\
\text { sepsis }\end{array}$ & $\begin{array}{l}\text { Meropenem, } 0.4 \mathrm{~g} \text {, q8h, } 7 \text { days and } \\
\text { ceftriaxone, } 1.5 \mathrm{~g}, \mathrm{qd}, 7 \text { days }\end{array}$ & Improve \\
\hline 9/ EAE1 & Pediatrics & $\begin{array}{c}\text { Severe pneumonia, } \\
\text { gastrointestinal, dysfunction }\end{array}$ & None & Severe pneumonia & Ceftriaxone, $0.5 \mathrm{~g}$, qd, 7 days & Improve \\
\hline 10/KPN2 & Neonatology & Neonatal pneumonia, ICH & None & Neonatal pneumonia & $\begin{array}{l}\text { Piperacillin/tazobactam, } \\
0.27 \mathrm{~g}, \text { bid, } 10 \text { days }\end{array}$ & Improve \\
\hline 11/KPN3 & Pediatrics & $\begin{array}{c}\text { Bronchopneumonia, sepsis, } \\
\text { MDS }\end{array}$ & $\begin{array}{c}\text { Drainage of } \mathrm{PE} \square \\
\text { BMA }\end{array}$ & $\begin{array}{l}\text { Bronchopneumonia, } \\
\text { sepsis }\end{array}$ & $\begin{array}{c}\text { Compound sulfamethoxazole, } 0.48 \mathrm{~g} \text {, } \mathrm{q} 12 \mathrm{~h}, 6 \\
\text { days }\end{array}$ & $\begin{array}{l}\text { Abandon } \\
\text { treatment }\end{array}$ \\
\hline $12 / \mathrm{ECO} 4$ & Pediatrics & Bronchopneumonia, CHD & None & Bronchopneumonia & $\begin{array}{c}\text { Compound sulfamethoxazole, 70mg, q12h, } 7 \\
\text { days }\end{array}$ & Improve \\
\hline $13 / \mathrm{KPN} 4$ & Neonatology & $\begin{array}{l}\text { Severe pneumonia, sepsis, } \\
\text { CHD }\end{array}$ & None & $\begin{array}{l}\text { Severe pneumonia, } \\
\text { sepsis }\end{array}$ & $\begin{array}{l}\text { Piperacillin/tazobactam, } \\
0.22 \mathrm{~g} \text {, bid, } 7 \text { days }\end{array}$ & Improve \\
\hline 14/ EAE2 & Neonatology & $\begin{array}{l}\text { Acute laryngitis, neonatal, } \\
\text { pneumonia }\end{array}$ & None & $\begin{array}{l}\text { Acute laryngitis, } \\
\text { neonatal pneumonia }\end{array}$ & $\begin{array}{l}\text { Cefoperazone/sulbactam, } \\
\text { 0.2g, q12h, } 7 \text { days }\end{array}$ & Improve \\
\hline 15/ ECO5 & $\begin{array}{l}\text { Pediatric } \\
\text { surgery }\end{array}$ & AGA, peritonitis, HBV & None & AGA, peritonitis & Imipenem, $0.27 \mathrm{~g}, \mathrm{q} 6 \mathrm{~h}, 6$ days & Improve \\
\hline 16/ KPN5 & Pediatrics & $\begin{array}{c}\text { Severe pneumonia, } \\
\text { gastrointestinal, dysfunction }\end{array}$ & None & Severe pneumonia & Piperacillin/tazobactam, $0.5 \mathrm{~g}$, bid, 7 days & Improve \\
\hline 17/ ECO6 & Pediatrics & $\begin{array}{l}\text { Bronchopneumonia, } \\
\text { gastrointestinal, dysfunction }\end{array}$ & None & Bronchopneumonia & Cefoperazone/sulbactam, $0.4 \mathrm{~g}$, bid, 11 days & Improve \\
\hline 18/ ECL1 & Neonatology & $\begin{array}{l}\text { Neonatal pneumonia, } \\
\text { hyperbilirubinemia }\end{array}$ & None & Neonatal pneumonia & $\begin{array}{l}\text { Cefoperazone/sulbactam, } \\
0.14 \mathrm{~g}, \mathrm{q} 12 \mathrm{~h}, 10 \text { days }\end{array}$ & Improve \\
\hline 19/KPN6 & Neonatology & $\begin{array}{c}\text { Premature infant, } \\
\text { bronchopneumonia, GERD }\end{array}$ & None & Bronchopneumonia & Ceftizoxime, $0.12 \mathrm{~g}$, q8h, 6 days & Improve \\
\hline 20/ ECO7 & $\begin{array}{l}\text { Pediatric } \\
\text { surgery }\end{array}$ & AGA, peritonitis & $\begin{array}{l}\text { Laparoscopic } \\
\text { appendectomy }\end{array}$ & AGA, peritonitis & $\begin{array}{l}\text { Cefoperazone/sulbactam, } 0.8 \mathrm{~g} \text {, bid and } \\
\text { metronidazole, } 0.5 \mathrm{~g} \text {, q8h, } 5 \text { days }\end{array}$ & Cure \\
\hline
\end{tabular}


${ }^{a}$ SMA, Serratia marcescens; KOX, Klebsiella oxytoca; ECO, Escherichia coli; KPN, Klebsiella pneumonia; EAE, Enterobacter aerogenes; ECL, Enterobacter cloacae.

${ }^{b}$ NICU, neonatal intensive care units; PICU, pediatric intensive care unit.

${ }^{c} \mathrm{NRF}$, neonatal respiratory failure; HIE, hypoxic-ischemic encephalopathy; CPR, cardiopulmonary resuscitation; MODS, multiple organ disfunction syndrome; CHD, congenital heart disease; ALL, acute lymphoblastic leukemia; ICH, intracerebral hemorrhage; MDS, myelodysplastic syndrome; AGA, acute gangrenous appendicitis; HBV, hepatitis B virus; GERD, gastroesophageal reflux disease.

${ }^{d}$ BAL, bronchoalveolar Lavage; PE, pericardial effusion; BMA, bone marrow aspiration.

${ }^{e} \mathrm{CRE}$, carbapenem-resistant Enterobacteriaceae 